\title{
Os registos clínicos e a codificação
}

Raquel Braga*

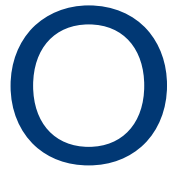
s registos clínicos são a memória de um médico, são uma preciosa ajuda à prática clínica, auxiliando e promovendo o raciocínio clínico, permitindo arquivar as impressões subjectivas e os dados objectivos, servindo de suporte clínico e legal e constituindo uma base importantíssima para o processo de formação e investigação em Medicina. ${ }^{1,2}$

A codificação, por sua vez, permite harmonizar e uniformizar, ou categorizar com códigos as diversas expressões pessoais que o doente relata, os diferentes e personalizados procedimentos que efectuamos em determinado caso clínico ou as nossas duvidosas, incertas ou rigorosas avaliações diagnósticas.

De uma forma generalizada, a classe médica, a nível da Medicina Geral e Familiar, aderiu aos diferentes sistemas informáticos de registos clínicos em uso. Para a maior parte dos médicos de família portugueses, longe estão os tempos dos registos clínicos escritos em papel.

Quando temos de recorrer aos ficheiros em papel para recuperar um documento, é com algum saudosismo e admiração que percorremos com o olhar os nossos antigos registos, em que a continuidade era mais aparente e a percepção da evolução do caso clínico mais evidente. Neles estão espelhados também a nossa alma e estado espírito, através da letra mais aprimorada ou mais irregular; a pressão do tempo, através de texto mais cuidado ou das palavras e frases inacabadas; a cadência com que decorreu a consulta, através da fluidez com o que o registo foi redigido e desenhado no papel...

Depois de recentemente fazer o exercício de me distanciar e observar os registos clínicos no Sistema de Apoio ao Médico (SAM) para comentar o nosso trabalho com o meu interno, e depois de passar pela experiência de auditar alguns processos clínicos de dife-

* Directora da Revista Portuguesa de Medicina Geral e Familiar rentes colegas, não pude deixar de reflectir acerca do caminho que os registos clínicos começam a levar nos dias de hoje.

Longe de serem a memória do médico, de o auxiliarem a recordar o que o doente disse em determinado contexto, parte importante dos registos clínicos começa a ser um seco repositório de classificações da Classificação Internacional de Cuidados de Saúde Primá$\operatorname{rios}(\mathrm{ICPC}){ }^{3}$

Ora, se um registo é, em muitos casos, um juízo clínico, sendo já interpretativo e não se limitando a ser uma descrição, uma codificação é definitivamente um rótulo homogéneo que se coloca a uma situação que por vezes ainda não amadureceu para ter sequer um nome...

Na nossa prática clínica, muitas vezes lidamos com sintomas vagos, mal definidos, que surgem em fases precoces da doença, que nem chegam a tornar-se doença ou transformar-se num problema de saúde. Apesar de a ICPC estar preparada para lidar com estas subtilezas da nossa especialidade, duvido que, em todos os momentos, estejamos preparados, para ali mesmo, no momento, por vezes demasiado breve e espartilhado da consulta, fazermos com que tudo o que descrevemos e ajuizamos vire um código, sabermos a que categoria cada sintoma ou impressão clínica pertence... O problema das classificações não reside na ICPC, mas sim na forma como ela é utilizada.

A maior parte dos clínicos não faz investigação, a maior parte dos clínicos dedica-se apenas à clínica e especializa-se no acto maior da Consulta. Interrogo-me então - porque deixaram alguns dos clínicos, sobretudo esses que só fazem clínica, de fazer na mesma os seus registos em texto livre para os passarem a fazer única e exclusivamente através de uma classificação que poucos estudaram e poucos dominam?

Que memória é esta que tão pouco nos servirá no futuro, a nós médicos? Tenho dúvidas que este tipo de registo meramente codificado e tão pouco prolixo tenha 
o suficiente rigor para, não permitindo a sua auditoria no que concerne ao rigor da descrição do que foi relatado, vir a servir de base de investigação no futuro.

A descrição do que se ouve, do que se interpreta ou do que se faz deve vir acompanhada, sempre que adequado e possível, da respectiva codificação, mas esta última não parece suficientemente expressiva para substituir a rica descrição semiológica do que se escuta e do que se subentende ou a complexidade e a incerteza do que se ajuíza.

Nesta edição, publicamos dois estudos originais que baseiam a sua investigação em registos clínicos. ${ }^{4,5} \mathrm{As} \mathrm{li-}$ mitações deste tipo de estudos que serão no futuro cada vez mais vulgares entre nós (felizmente! sobretudo se forem de boa qualidade...), poderão ser colmatadas através do desenvolvimento de procedimentos de registo e de codificação. Estes procedimentos têm de assentar na discussão e na sistematização da forma como estes devem ser praticados.

Quantos e quais serão os médicos que fazem os seus registos e codificações com suficiente rigor para que a sua prática possa ser objecto de inclusão num estudo deste género? Todos ou só alguns?

Talvez fosse interessante começar por fazer um estudo que respondesse a esta questão...

Nesta edição falamos também acerca de $e$-counselling e da sua importância crescente. Abordamos, de novo, o uso do e-mail na consulta. ${ }^{6}$

A forma como alguns sistemas informático estão desenvolvidos (como por exemplo o SAM) não permite, neste momento, efectuar registos no local dos registos contínuos (SOAP) sem abertura de um contacto, o que actualmente não se pode nem deve fazer, sem o consentimento do utente, uma vez que, nos devidos casos, tal acto médico condiciona o pagamento de uma taxa moderadora. $^{7}$

Ora, para além das consultas por email, temos muitas vezes contactos telefónicos, contactos por via de terceiros, ou o envio directo para o sistema informático, sem o conhecimento prévio do utente, de resultados de exames auxiliares de diagnóstico, que nos devem suscitar a necessidade e o rigor do registo da informação no local apropriado. ${ }^{2}$ Muitas vezes, nestes contex- tos de consultas não presenciais, para além do registo de informação para mais tarde recordar, há até juízos clínicos, procedimentos aconselhados ou efectuados. Em muitos destes casos, não há propriamente a possibilidade ou viabilidade prática de pedir consentimento expresso ao doente para abertura do contacto, pelo que a dificuldade do registo nestas situações deveria ser contornada pela possibilidade real de podermos efectuar os registos sempre que necessário e nos locais mais indicados.

Acerca desta questão central dos registos e das codificações, não posso terminar sem salientar e sem me congratular com a habitual generosidade dos médicos de família...

Sem pestanejarem, a maioria dos colegas que aderiram aos registos nos sistemas informáticos, assumiram com a naturalidade e o auto-didactismo do costume a arte de codificar e passaram a fazê-lo com tal desenvoltura que já nem recordam que, há apenas alguns anos, só uma minoria entre nós o fazia. Aliás, como nos Hospitais hoje ainda ocorre... onde há médicos que têm, como única tarefa demorada e remunerada, o acto de codificar o que os outros colegas registam...

\section{REFERÊNCIAS BIBLIOGRÁFICAS}

1. Weed LL. Medical records that guide and teach. N Engl J Med 1968; 278: 593-600, 652-7.

2. Queiroz MJ. O SOAP revisitado. Rev Port Clin Geral 2009 Mar-Abr; 25 (2): 221-7.

3. World Organizations of National Colleges, Academies, and Academic Associations of General Practitioners / Family Physicians (WONCA). ICPC-2: International Classification of Primary Care. 2nd ed. Oxford, NY: Oxford University Press; 1998.

4. Martins S. O peso da mente feminina: associação entre obesidade e depressão. Rev Port Clin Geral 2012 Mar-Abr; 28 (3): 163-6.

5. Sá MC, Balsa MJ....Anticoagulação oral nos muito idosos e seus determinantes clínicos. Rev Port Clin Geral 2012 Mar-Abr; 28 (3): 168-76.

6. Yaphe J. E-counselling: taking e-mail communication with patients one step further. Rev Port Clin Geral 2012 Mar-Abr; 28 (3): 159-60.

7. Governo de Portugal. Taxas Moderadoras - Perguntas frequentes. Disponível em: http://www.portugal.gov.pt/pt/os-ministerios/ministerio-da-saude/documentos-oficiais/20111222-pf-taxas-moderadoras.aspx [acedido em 26/06/2012].

\section{ENDEREÇO PARA CORRESPONDÊNCIA}

director@rpcg.apmcg.pt 